\title{
LAS PRÁCTICAS CORPORALES EN LA EDUCACIÓN CORPORAL
}

\author{
DRA. LUZ ELENA GALLO CADAVID \\ Profesora Titular de la Universidad de Antioquia, Grupo de Investigación: Estudios en Educación \\ Corporal (Medellín - Antioquia - Colombia) \\ Email: luzelenagalloc@hotmail.com
}

\begin{abstract}
RESUMEN
Este trabajo tiene como propósito abordar la motricidad a partir de prácticas corporales como el danzar, jugar y caminar, así como el gesto y las sensaciones kinestésicas en el horizonte de la Educación Corporal. Interesa mostrar la Motricidad como esa experiencia que nosotros mismos hacemos del cuerpo (leiblich) para establecer una relación con la Educación. La motricidad, en el horizonte de la Educación Corporal, realza las prácticas corporales no con el fin de prescribir prácticas institucionalizadas o normalizadas sino con la pretensión de favorecer experiencias para disponer estados de afección, como ese pathos que sucede ocurriendo, afectando, tocándonos y actuando sobre nosotros, lo cual supone una mirada de la Educación bajo la figura del acontecimiento, que no pretende planificar lo sensible ni normativizar la experiencia.
\end{abstract}

PALABRAS CLAVES: Educación corporal; prácticas corporales; motricidad; experiencia del propio cuerpo.

\section{INTRODUCCIÓN}

Este artículo se inscribe en el marco de la investigación de corte teóricodocumental: El cuerpo en perspectiva de una hermenéutica de la sensibilidad como 
ámbito de estudio de la Educación Corporal,' en el cual le otorgamos un valor superior al cuerpo en la Educación. Cuando nos preguntamos por las formas de expresión corporal en perspectiva pedagógica, estamos asumiendo la motricidad como una práctica corporal, puesto que, de conformidad con la dimensión simbólica del cuerpo, dichas prácticas corporales son, ante todo, simbologías corporales, nos hacen comunicar algo, son modos de decir del cuerpo, modos y formas de "uso" del propio cuerpo y se refieren a las disposiciones, disponibilidades y no disposiciones del propio cuerpo.

Mediante una práctica corporal, el cuerpo practica formas de la experiencia, porque con el movimiento corporal se expresan modos de ser de la persona, y la percepción que esta persona tiene de ello puede generar una determinada experiencia. Un ejemplo de ello es la realización de una práctica corporal en la que se repita un gesto con variaciones de la velocidad, o aquellas prácticas "somáticas" que reúnen métodos orientados hacia el aprendizaje de la conciencia del cuerpo desde la perspectiva de la experiencia personal². Por medio de una práctica corporal podemos saber de la experiencia y, por tanto, sobre el cuerpo. Si el ser humano se produce a sí mismo, esto significa que a partir de las formas de expresión del cuerpo se hacen visibles formas de la experiencia de la persona que lo transportan a otro marco de reflexión y de sensibilidad. Digamos que se acogen las variaciones de velocidad del cuerpo para abrir la percepción de la experiencia corporal. Con ello exponemos una idea pedagógica de la formación destacando que esa persona se hace en la percepción, se hace en el cuerpo. Así, las prácticas corporales se convierten en espacios de experimentación y aquel gesto aprendido de la danza pone en relación la percepción, el cuerpo y el saber. "El bailarín no tiene el oído en las orejas. Sus músculos oyen el sentir del mundo mediante melodías que hacen contraer y distender sus articulaciones mediantes gestos. Todo su cuerpo está atento a desplegarse del melos para articularlo en ritmos que hablan otro lenguaje". (DE SANTIAGO, 2004, p. 517). Dice Zaratustra: mis talones se irguieron, los dedos de mis pies escuchaban para comprenderte. Lleva, en efecto, quien baila sus oídos ien los dedos de los pies!. (NIETZSCHE, 2009, p. 3।4, segunda canción del baile).

Cuando establecemos relación entre las prácticas corporales y la educación, nos orientamos hacia una configuración estética de la existencia: ipor qué baila

I. Investigación financiada por el Comité para el Desarrollo de la Investigación (CODI), Universidad de Antioquia (20II-20I2).

2. Castro, Julia y Uribe, Marta (1998, p. 4I) mencionan que la Eutonía de Gerda Alexander, la Técnica de Alexander de Mathias Alexander, la Antigimnasia de Thérèse Bertherat, el Body-Mind Centering de Bonnie Bainbridge Cohen, el método Feidenkrais de Moshe Feldenkrais, los Fundamentales de Laban-Bartenieff, y los Soma-ritmos de Ninoska Gómez, han desarrollado diferentes estrategias pedagógicas somáticas hacia la educación del movimiento consciente. 
Zaratustra? En primer lugar, para protegerse del espíritu de la pesadez, y, en segundo lugar, porque quiere enseñar cómo se vuelve uno ligero; la danza transforma y metamorfosea al bailarín, haciendo que la pesadez se convierta en ligereza.

Ahora la esencia de la naturaleza debe expresarse simbólicamente; es necesario un nuevo mundo de símbolos, de momento todo el simbolismo corporal completo, no sólo el simbolismo de la boca, del rostro, de la palabra, sino el gesto íntegro del baile que mueve rítmicamente todos los miembros. (NIETZSCHE, 1998, §2, p. 70).

La motricidad del propio cuerpo hace también referencia a la noción de comportamiento simbólico, a un ser que tiene la posibilidad de expresión en perspectiva múltiple. (MERLEAU-PONTY, 1976, p. 177). Una práctica corporal se constituye en un modo de acción; así, la motricidad se expresa en sus prácticas corporales y, al expresarse, constituye nudos de significación. La motricidad tiene que ver con una determinada expresión de la corporalidad, que se distiende como unidad significativa porque, lejos de posturas mecanicistas y vitalistas, lo que nos importa es la experiencia que hace el propio cuerpo en movimiento.

Sabemos que la motricidad se puede explicar a partir de los discursos orgánicos, en su fisicalismo y a la luz de los aportes de la Fenomenología que, partiendo de la existencia corporal, revisa las tendencias unilaterales de la modernidad; autores como Husserl, Merleau-Ponty, Barbarás y Waldenfels nombran de manera diferenciada dos maneras distintas de ser cuerpo: la un sólido o volumen cualquiera, material o geométrico (Körper), y la de un ser de carne, viviente y mortal (Leib). Esta peculiaridad terminológica ha sido especialmente aprovechada por la Fenomenología, a partir de Edmund Husserl, para exponer el sentido filosófico de dicha distinción y repercute en la manera de explicar cómo nos movemos corporalmente.

Cuando nos referimos a la motricidad en su discurrir significativo, estamos entendiendo, con Van Den Berg ( 1952), que los movimientos del cuerpo humano, tomados en forma aislada, son simples cambios que varían, desplazamientos de un órgano o un sistema de órganos. Los movimientos vienen a significar en el conjunto hombre más situación, es decir, la forma de experimentar el cuerpo en movimiento se nos da a partir de una espacialidad de situación, que es vivida y experimentada no en una espacialidad de posición calculada y objetual. Dicha espacialidad se orienta hacia un horizonte; un ejemplo de ello nos lo ofrece Merleau-Ponty (1976, p. 237) cuando dice:

[... la lancha de fútbol no es, para el jugador en acción, un 'objeto', está recorrida por líneas de fuerza, articulada en sectores que provocan ciertos modos de acción. El terreno no está dado, está presente en sus intenciones, el jugador constituye un todo con él y siente la dirección del objetivo. 
La espacialidad y el movimiento corporal son interpretados por Merleau-Ponty como dirigidos hacia un mundo animado de significados. De allí que la motricidad sea un haz de intencionalidades; sin embargo, iqué entendemos por intencionalidad? En primer lugar, es necesario diferenciar la intencionalidad de acto, de nuestros juicios, nuestras tomas de posición o conciencia tética, y la intencionalidad motriz, que algunos nombran como preintencional, latente o conciencia pre-tética. De una parte, la intencionalidad de acto es tener conciencia clara y racional de algo, es temática, conceptual, discursiva e intelectualista. De otra parte, la intencionalidad motriz "la constituye la unidad natural y antepredicativa del mundo y de nuestra vida". (MERLEAU-PONTY, 1975, p. 17). La intencionalidad motriz ${ }^{3}$ es conciencia perceptiva, es una intencionalidad que no se deja dirigir por una direccionalidad, no se deja conducir ni prescribir y no tiene un estereotipo. Podríamos decir que no es un dispositivo mecánico, sino que se distiende un poco, como posibilidad de significación.

En segundo lugar, la intencionalidad motriz nos ayuda a entender de otra manera la motricidad en perspectiva pedagógica, como aquella práctica corporal que no está dirigida a una finalidad predeterminada, pues no se trata de movernos en direcciones únicas ni bajo indicaciones estáticas; preferimos entender la motricidad como potencia y no como un acto, porque como potencia deviene en multiplicidad de perspectivas, direcciones, desplazamientos, trayectos, aperturas, no hay punto de llegada; prácticas corporales en términos de multiplicidad y en perspectivas distintas. Gracias a que el cuerpo en movimiento nos permite hacer experiencia, los movimientos corporales le impregnan sentidos al cuerpo. Las prácticas corporales son portadoras de sentido y, como tienen que ver con un uso del cuerpo ofrecen, a su vez, posibilidades de interpretación.

Suponiendo que uno apreciase el valor de una música a tenor de lo que ella pudiese contarse, calcularse y reducirse a fórmulas, iqué absurdo sería una valoración 'científica' semejante de la música! ¿Qué es lo que uno habría comprendido, entendido y sabido de ella? Nada, absolutamente nada de lo que en ella es propiamente música. (NIETZSCHE, 2002, p. 373).

A lo largo de este texto, nos acercamos a varios ejemplos de prácticas corporales para comprenderlas en el horizonte de la Educación Corporal: la danza

3. En el texto Los discursos de la Educación Física contemporánea se dice que para ilustrar la idea de intencionalidad motriz u operante y diferenciarla de la intencionalidad de acto, Merleau-Ponty se vale de un ejemplo del aprendizaje como la adquisición del hábito de bailar. En el baile es el cuerpo el que atrapa y comprende el movimiento, es la captación motriz de una significación motriz. Resulta de ello que los lugares del espacio no se definen como posiciones objetivas, sino que se presentan como una situación. (GALLO, 20I0, p. 40-4I). 
como práctica corporal estética de la alegría dionisiaca (Nietzsche), el juego como dimensión estética (Schiller), el caminar como apertura de horizontes (Masschelein), la dimensión gestual en el orden simbólico (Le Breton), las sensaciones kinestésicas como constitución de la percepción (Husserl), que, entre otros, se convierten en la posibilidad para desplegar un pensamiento de las prácticas corporales como despliegue de potencias.

\section{MATERIALES Y MÉTODOS}

En esta investigación retomo de Nietzsche, Schiller, Masschelein, Le Breton y Husserl ejemplos de prácticas corporales y los coloco en un plano de inmanencia: la Educación Corporal, que es una forma de desterritorializar conceptos o arrancarlos de su dominio para re-territorializar y crear nuevos agregados. Esto obedece a un trabajo de investigación teórico-documental, proceso que se lleva a cabo a partir de la hermenéutica donde se hace un ejercicio de indagación en forma de espiral sobre el problema de estudio que se centra en el análisis y la interpretación -hermeneusis- de documentos o textos escritos. Este ejercicio hermenéutico no parte del presupuesto de que los textos encarnan una unidad original y cristalizada de sentido, nos situamos en la noción de sentido de Gilles Deleuze, como entidad heterogénea y múltiple, no independiente, sino necesariamente ligada a la interpretación. El análisis de los textos de los autores se hizo siguiendo el método propuesto por Heinz-Hermann Krüger (1999), quien diferencia tres fases para la interpretación de los textos: preparatoria, inmanente y coordinada.

\section{INSTRUMENTOS}

Se utilizó la técnica de análisis documental para los textos con el instrumento de fichas de contenido. Es inherente a la lectura de los autores, las conexiones múltiples con otros autores, otros libros, otros quehaceres teóricos. Y a partir de estas conexiones nos corresponde proseguir las derivas de lectura a las que nos invitan los autores, hibridando los textos con otros, en un devenir de lectura en clave pedagógica a la luz de la Educación Corporal.

\section{DISCUSIÓN}

\section{DANZAR COMO PRÁCTICA CORPORAL ESTÉTICA}

En el marco de la estética del arte, Nietzsche encontró, como recursos estéticos, la danza, el canto y la poesía, elementos de la tragedia griega que expresan 
la estética dionisíaca que son expresiones de la vida misma. Aunque la danza o el baile requieren de cierto dominio técnico, también se realiza de manera "libre", con diferentes formas de expresión de la corporalidad; en ella los movimientos y los gestos forman una expresión mucho mayor que la suma de sus partes. Aunque para algunos esta práctica corporal se ve limitada por las posturas y movimientos del cuerpo, otros parecieran que "tienen su genio en los pies"; sin embargo, lo que nos importa destacar es el sentido formativo de la danza, su valor transformativo.

La danza forma parte de la estética dionisíaca y es el cuerpo el que se eleva con la danza a un lugar privilegiado. La danza, en ocasiones, estimula, libera las tensiones de lo real, abre pasiones, recrea la imagen de hombre por medio de la expresión de sus gestos y movimientos; es un lenguaje en el que se unen la melodía, el tono, el ritmo y la armonía, transforma la pesadez en ligereza, se fundamenta en la alegría, brota de ella, "la bella apariencia de sus gestos, que desvelan lo profundo. Y, en lo profundo, el dios Dionisio se mueve como un dios danzarín, un artista que manifiesta su fuerza y poder creativo, que es el de trasgredir, trascender y transformar". (DE SANTIAGO, 2004, p. 5I0).

Cuando decimos que el cuerpo se eleva a un lugar privilegiado, estamos diciendo que el hombre que danza experimenta algo que Plessner (1960, p. 5362) denomina "principio excéntrico" o estar "fuera de si". La excentricidad hace que el hombre experimente, por un lado, que tiene cuerpo y, por otro, que es cuerpo. Estar "fuera de si" no significa dejar el mundo; el hombre dionisíaco es ese hombre en devenir que es capaz de transportarse y elevarse por encima de sí mismo: "ahora soy ligero, ahora vuelo, ahora me veo a mí mismo por debajo de mí”. (NIETZSCHE, 2009, p. 75).

"En el estado dionisíaco primordial, todo ritmo continúa hablando a nuestros músculos, imprimiendo al cuerpo un movimiento que, por su repetición, hace salir el alma de ella misma. Es al ritmo al que debe obedecer el verso de tocar el corazón del hombre". (DE SANTIAGO, 2004, p. 5I4). Para los griegos, la danza pone el alma en movimiento y para redescubrir la vida es necesario el cuerpo; es la danza la que se penetra en el cuerpo, provocando un estado de exaltación; la danza le devuelve a la música su dimensión corporal, la danza como lenguaje poético otorga una simbología corporal; la danza es una forma de experimentar los modos de decir del cuerpo. Aquel que no danza no siente los ritmos acompasados de su cuerpo.

Ahora bien, recordemos que, desde el punto de vista de algunas tradiciones, el alma miraba con desprecio al cuerpo, pero ahora "el cuerpo es la gran razón, es una pluralidad dotada de un único sentido" (NIETZSCHE, 2009, p. 64); el cuerpo es plural, pluralidad de expresiones que vemos por medio de la danza, pues el bailarín no permanece pesadamente en un sitio, gira, se desplaza, cambia de direcciones y 
de ritmos, "baila sobre los pies del azar". (NIETZSCHE, 2009, p. 240). También Nietzsche espera que las palabras se muevan como en una danza, que los conceptos bailen, que haya en ellos movimiento, desplazamiento y que provoquen nuevas figuras. Dionisio es el dios que danza bajo las palabras, por lo que habrá entonces que poner a danzar a las palabras y a las frases.

Hablar del pensamiento como danza implica asumir lo provisional, lo inesperado, lo inestable y el riesgo; la danza representa un equilibrio mudable que se crea constantemente en la misma práctica corporal en sus gestos, sus figuras, sus ritmos, ipodemos llegar al pensamiento bailando? Recordemos a Nietzsche en La Gaya Ciencia:

[...] no somos de esos que sólo llegan a tener ideas entre libros, por impulso de libros; estamos acostumbrados a pensar al aire libre, andando, saltando, subiendo, bailando, y donde más nos gusta hacerlo es en montañas solitarias o justo al lado del mar, allí donde incluso los caminos se hacen reflexivos. (NIETZSCHE, 2002, §366).

Desde la perspectiva de la Educación Corporal, lo que pedimos de la danza como práctica corporal es, sobre todo, que nos haga capaces de poner la mirada en escena móvil, con posibilidades cambiantes, con multiplicidad de puntos de vista, de perspectivas y de horizontes: iacaso el mundo de las perspectivas no es consecuencia de un pensamiento bailarín? Virtuoso el bailarín que abre significados a perspectivas nuevas a partir de su devenir azaroso, aquel que despliega su pensamiento en-movimiento, aquel cuyo modo de pensar es la movilidad, aquel que en su fugacidad puede captar el nacimiento del pensamiento. En términos pedagógicos, Zaratustra también nos enseña con el lenguaje de la danza, nos pone ante una forma de lenguaje "corporal" que, al tener el ritmo de la danza, deviene en innumerables ondas de significado.

\section{JUGAR COMO DIMENSIÓN ESTÉTICA}

El juego desestabiliza, quiebra la unidad en multiplicidad, abre distintas perspectivas y favorece una diversidad de miradas e interpretaciones. Kant, Schiller, Nietzsche y Gadamer se sirven de la figura del juego en tanto constituye una forma suprema y valiosa de la relación del hombre con el mundo. El juego apela a la dimensión creadora y lúdica de la existencia humana. Una de las raíces fundamentales de la idea de juego la encontramos en la referencia que hace la estructura griega del agon. Aunque el impulso agonal es competencia y rivalidad,

[...] el motivo del agon adquiere una mayor relevancia cuando Nietzsche lo relaciona puramente ético a un principio estético, iqué problema se abre entre nosotros cuando 
investigamos la relación entre el agonismo y la concepción de la obra de arte!, pues toda fuerza creativa se despliega y se manifiesta luchando. (DE SANTIAGO, 2004, p. 554-555).

El juego es siempre una lucha por algo, es contienda, incertidumbre, es una puesta a prueba de destrezas y habilidades, es inclemente; aunque desde Heráclito el juego no tiene un por qué, no tiene finalidad alguna, particularmente en el agon los juegos significan, exigen un por qué "precisamente porque el juego se guía también por el principio de razón suficiente que hay en cada movimiento". (HOLZAPFEL, 2003, p. 74). Incluso esto hace que autores como Thierry Lenain, Eugen Fink, Frederick Johannes Buytendijk, Johan Huizinga y Roger Caillois desarrollen la idea de razón lúdica, en la que, paradójicamente, el juego es algo que no se deja guiar por una finalidad o por una meta, y a la vez, es el escenario mismo del crear; dicho de otro modo, la finalidad que tiene el juego descansa únicamente en él mismo. Por ejemplo, el niño convierte el juego en el modelo esencial de la actividad creadora y en el acontecer del juego representa su verdadera esencia. Al margen del por qué, el niño crea sus propios personajes, que constituyen su mundo; pareciera que el niño tiene un poder ilimitado de fantasía para crear.

Es el juego el que se juega o se desarrolla; incluso, el modo de ser del juego no es tal que, para que el juego sea jugado, tenga que haber un sujeto que se comporte como jugador; el juego es pura realización del movimiento. "El movimiento que en estas expresiones recibe el nombre de juego no tiene un objetivo en el que desemboque, sino que se renueva en constante repetición". (GADAMER, 2003, p. I46). El hombre que juega sigue siendo un hombre que se comporta; algo que caracteriza el comportamiento en el juego es su carácter tanto de repetición como de renovación; por medio del juego el hombre se experimenta.

Lo importante es el juego en su acontecer mismo, lo significante es ese algo que está en juego. Platón ${ }^{4}$ establece una relación entre culto y danza, música y juego, e intuye el carácter estético del juego al analizar la actitud mimética del artista: aquí la imitación constituye un juego; posteriormente, Schiller equipara la belleza con el juego a partir de la tesis de que el juego hace al hombre completo en tanto desarrolla su doble naturaleza sensible y racional; la belleza significa la consumación de una humanidad dualista. Schiller defendía la belleza como el resultado de un "instinto lúdico", que, como principio de acción, engloba tanto el impulso sensible como el formal o intelectivo. En el juego el hombre se representa esencialmente a sí mismo, se reconoce como hombre en cuando forma viva; de ahí el imperativo schilleriano que establece que "el hombre sólo es enteramente hombre cuando

4. Platón, Leyes, II, 653 Cf.: Platón (2003). Diálogos: obra completa. Madrid: Gredos. 9v. 
juega”. (SCHILLER, 1990, p. 24I). Mientras para Schiller los dos impulsos se reconcilian con el "impulso de juego" según la razón, en Nietzsche los impulsos apolíneo y dionisíaco se unen en la forma artística de la tragedia, y se representa en la metáfora del juego en la que la vida se "juega".

Desde la perspectiva de la Educación Corporal, importa el juego como práctica corporal no solamente por su actitud desinteresada sino también porque jugar significa transformar, transformarse, crear y crearse. El juego es para el hombre un acontecer y, a la vez, es una forma de expresión simbólica del acontecer de la vida; quizás, lo que importa del juego no es su carácter de distracción sino que en el jugar se da una especie de seriedad. Más allá de que el niño construya castillos de arena y luego los destruya, lo que importa del juego es su dimensión creadora, esa expresión creativa de la vida. "Una vez más Zaratrustra, de la misma manera que había increpado a los hombres superiores porque no sabían danzar y no sabían reír, vuelve a su pedagógica cantinela: los hombres superiores también saben jugar. Para poder superarse a sí mismo y poder crear por encima de sí mismo, hay que aprender a jugar, a saber jugar". (DE SANTIAGO, 2004, p. 573).

\section{CAMINAR COMO APERTURA DE HORIZONTES}

Caminar, en el sentido de dar pasos, de estar en marcha, evoca una imagen que hace posible pensar el caminar como una práctica corporal para explorar nuevas maneras de ver y de abrir horizontes. Tal vez nos estamos refiriendo, con Masschelein, a un caminante y viajero que no se mueve en una dirección única porque prefiere los senderos que se bifurcan y que toman varias direcciones.

Benjamin (1987, p. 22), en Dirección única, nos dice:

La fuerza de una carretera varía según se la recorra a pie o se la sobrevuele en aeroplano [...] Quien vuela, sólo ve cómo la carretera va deslizándose por el paisaje[...] Tan sólo quien recorre a pie una carretera advierte su dominio y descubre cómo en ese mismo terreno, que para el aviador no es más que una llanura desplegada, la carretera, en cada una de sus curvas, va ordenando el despliegue de lejanías, miradores, calveros y perspectivas.

La práctica corporal del caminar está relacionada con mirar, con abrir los ojos, con estar atentos, con generar una nueva mirada, lo cual no es sinónimo de adquirir una perspectiva o una visión determinadas, sino que equivale a desplazar nuestra mirada; "abrir los ojos es mirar lo que es evidente cuando estamos atentos o expuestos". (MASSCHELEIN, 2006, p. 299). En perspectiva pedagógica, es algo así como dislocar la propia mirada para ver de un modo diferente; vemos lo visible: terrenos, curvas, lejanías, y no nos quedamos sólo en ese transcurrir "pasivo"; caminar puede permitirnos una experiencia para abrirnos paso en el camino. 
Masschelein (2006, p. 297) nos dice que "caminar no es que nos ofrezca una perspectiva mejor ni una comprensión más cierta y completa, ni nos permite superar los límites de nuestra perspectiva, caminar nos permite una mirada más allá de cualquier perspectiva, una visión o una mirada que nos transforma, como es experiencia, también nos conduce". La mirada que tenemos cuando caminamos por un sendero será siempre diferente porque corresponde a otro punto de vista, a otra perspectiva; ejemplo de ello es que vemos distinto un sendero o una calle caminando que si lo recorremos en automóvil o en avión: no solo cambian las perspectivas de arriba-abajo, sino que "vemos" de un modo distinto; son diferentes modos de vincularnos al mundo, con lo presente y con lo que está presente. Nos indica Benjamin: aquel que vuela, solo ve, pero el que camina conoce el poder que conduce, es decir, experimenta cómo ese algo se presenta así mismo, se vuelve evidente y dirige nuestra alma, nos atraviesa. El camino no puede tocar a quien lo sobrevuela, mejor dicho, no puede atravesarlo ni determinar su ruta.

\begin{abstract}
¿Quién no se ha sorprendido alguna vez al salir del metro al aire libre y verse caminando, arriba, a plena luz del sol? Y, sin embargo, el sol brillaba con la misma claridad unos minutos antes, cuando él bajó. Así de rápido ha olvidado qué tiempo hacía en el mundo de arriba. Y éste, a su vez, lo olvidará con igual rapidez. Pues, ¿quién puede decir de su existencia algo más que esto: que ha pasado por la vida de dos o tres personas con la misma dulzura y proximidad con que va cambiando el tiempo?. (BENJAMIN, 1987, p. 92).
\end{abstract}

Caminar es exponerse, estar fuera de lugar. De conformidad con la Educación Corporal, esta práctica corporal nos puede volver atentos, dislocar la mirada, ofrecer una mirada nueva frente a aquello que estábamos habituados a ver porque no nos conduce a un lugar determinado de antemano sino que nos lleva sin destino $u$ orientación alguna, desplazando entonces la mirada que teníamos; es, entonces, una actitud para con el presente. "Caminar es también aumentar la distancia crítica, lo que no significa lograr una meta-punto de vista, sino más bien una distancia que permite que la propia alma se disuelva desde dentro". (MASSCHELEIN, 2006, p. 300).

Podríamos decir que caminar es una expresión de la corporalidad que nos ayuda a pensar de otra manera la perspectiva pedagógica de la motricidad, en tanto no se inscribe en ningún horizonte, no ofrece tradiciones ni representaciones, no busca de antemano algo ni conduce hacia alguna perspectiva; brinda, simplemente, trayectos, insinúa líneas que atrapan, movilizan y hacen desviar la mirada; la línea no pretende mostrar ninguna escena ni representación, ayuda a pensar el movimiento corporal como apertura y posibilidad de una transformación. Para Masschelein (2006, p. 308) "caminar a lo largo de esa línea es caminar sin programa, sin objetivo, pero sí con una carga, con un encargo: ¿qué hay ahí para ver, para oír, para pensar?" 
Esta perspectiva pedagógica, esta práctica corporal opta por la posición de vulnerabilidad, incomodidad, inseguridad y riesgo. Como el sujeto de esa caminata es el sujeto de la experiencia, "importa poco no saber orientarse en una ciudad. Perderse, en cambio, en una ciudad como quien se pierde en el bosque, requiere aprendizaje. Los rótulos de las calles deben entonces hablar al que va errando como el crujir de las ramas secas, y las callejuelas de los barrios céntricos reflejarle las horas del día tan claramente como las hondonadas del monte. Este arte lo aprendí tarde". (BENJAMIN, 1990, p. 15).

Podemos decir que al caminar aprendemos del sentido de la experiencia sensible, de un cuerpo que se produce como experiencia de sentido a través de lo sensible, de un saber que se ejercita en el cuerpo, es decir, del sentido perceptivo del cuerpo. De hecho, la percepción tiene que ver con el aprendizaje y está en relación con el conocimiento y en el nivel de la sensibilidad; este modo de ser sensible que acontece en una práctica corporal nos pone en un lugar, en la valoración de lo sensible. La percepción, atendiendo a lo que hemos dicho respecto a las prácticas corporales, nos puede provocar una experiencia perceptiva; de hecho, sentidos y percepción, que constituyen experiencia de potencias e imponencias del cuerpo que acercan el sentir y el pensar. La percepción es también equívoca, falible, frágil y cambiante.

\section{EL GESTO COMO LENGUAJE CORPORAL}

Un gesto es revelador de un cierto lenguaje del cuerpo que puede producir un sentido, un significado, y además de eso, provocar sensaciones. Pero, iqué es el gesto? Antes de desarrollar su punto de vista sobre este concepto, Giorgio Agamben nos recuerda que, a finales del siglo XIX, la burguesía occidental había comenzado a percibir, aunque fuera de forma inconsciente, que estaba perdiendo sus gestos. Posteriormente, Isadora Duncan en el baile, las novelas de Marcel Proust, las películas del cine mudo y las actuaciones de Marcel Marceau y otros mimos reflejan un intento por recuperar y reinventar esos gestos perdidos.

La primera distinción que hace Agamben (2007) es la separación entre el gesto y la conducta dirigida a un fin; el gesto estaría desprovisto de finalidad es un «puro movimiento». La danza es gesto precisamente porque exhibe el carácter de los movimientos corporales. Y, por medio de esa exhibición, se deshace, desmiente su propio ocurrir, convirtiéndose en gestualidad pura, en medio sin fin. Bailar supone quedar suspendido entre el recuerdo (venir), el acontecimiento (devenir) y lo potencial (porvenir). «Y por eso mismo, la danza es inagotable». 
El gesto, junto con el rostro, también es lugar de exposición y revelación. El gesto es lenguaje. "Los movimientos del rostro participan de una simbología, son los signos de una expresividad que se muestra, que se presta a ser descifrada, aunque no sean totalmente transparentes en su significación”. (LE BRETON, 20 I0, p. 9l). Por ejemplo las mímicas, la dirección de la mirada, la posición de la cabeza y el movimiento de las manos son lenguajes anclados a los matices propios de la historia, a la cultura y al propio cuerpo, que se traducen en signos o, dicho de otro modo, en una simbólica corporal.

La segunda distinción es que el gesto, como acto expresivo, queda sin expresión. En otras palabras, en el núcleo de todo discurso permanece un vacío expresivo ante la imposibilidad de alcanzar una comunicación plena. En este sentido, Giorgio Agamben nos dice que, según los teóricos de la comedia del arte italiano, el gesto del Arlequín no tenía nada que ver con la historia que se desarrollaba en la escena, sino que su función era interrumpir los actos expresivos de los actores.

La gestualidad que vemos por medio de una práctica corporal está anclada a una trama simbólica y, cuando interesa interpretar los indicios significativos, hay que situar el movimiento en contexto, en situación. Por ejemplo la

ritualidad de la mirada cambia según las sociedades, corresponde al orden simbólico que varía no solamente de una cultura a otra, sino de un grupo social a otro. En este sentido, todo análisis demasiado rígido de la interacción de las miradas se expone a la desmentida de una realidad múltiple y contrastada. (LE BRETON, 20 I0, p. 129).

La gestualidad es un mediodecir de nosotros mismos, un susurro de la identidad personal, no una afirmación caracterológica; podemos decir, más bien, que la noción que articula cuerpo y palabra es el gesto. El gesto es, entonces, una modulación de la corporalidad; tanto el gesto corpóreo como el gesto corpóreo-lingüístico son dos modos de manifestación de la capacidad significativa del cuerpo, tanto con sentido lingüístico como gestual.

Para Merleau-Ponty (1975, p. 203) el gesto se entiende como movimiento corporal; "el sentido del gesto [... . no está tras él, se confunde con la estructura del mundo que el gesto diseña y que yo tomo por mi cuenta, se exhibe sobre el gesto mismo". La gestualidad, como lenguaje corporal, es expresión de la corporalidad y, como texto corporal, se lee a partir del propio cuerpo; esta es una característica del cuerpo para la Fenomenología: su carácter de apertura, su capacidad de apropiarse de núcleos significativos que superan y transfiguran sus poderes naturales. Es necesario advertir que los sentidos de la gestualidad son inmanentes a la expresión misma; el sentido no es algo que ya viene dado ni es algo ya constituido previamente a la expresión. El sentido se produce en un contexto, reside siempre en una orientación 
resultante de la relación de la persona con el mundo, orientación que trasciende en cada caso lo ya dado.

La gestualidad nos dice de un cuerpo que es, ante todo, expresión. Esto indica que es capaz de trascender lo ya dado, y lo dado puede ser su propia biología o las significaciones ya sedimentadas. El gesto trasciende la significación biológica del cuerpo, el gesto se dice a sí mismo: "una expresión gestual es reveladora de un modo de ser, de un cierto estado anímico; por ello, el supuesto de que el sentimiento o la emoción que expresa el gesto se halla oculto tras él, carece de valor; al contrario, la experiencia que tenemos de una afección como la alegría o la ira se halla en la expresión misma y puede decirse que se lee la alegría o la ira en el gesto mismo y no detrás de él”. (GALLO, 2010 , p. 65).

\section{LAS SENSACIONES KINESTÉSICAS COMO CONSTITUCIÓN DE LA PERCEPCIÓN}

La motricidad no está relacionada con la conciencia, no es un yo-pienso, sino un yo-puedo. A manera de ejemplo, el tacto no es una mera suma de tocarse -de sensaciones táctiles-, ni tampoco una suma de sensaciones táctiles + kinestesis, es un 'yo puedo'. (BARBARÁS, 1992). La percepción se comprende, entonces, a partir de la motricidad y la intencionalidad motriz es, por tanto, una forma de conciencia perceptiva. Así pues, la intencionalidad motriz es más originaria que la intencionalidad de la conciencia porque emana del cuerpo vivido (Leib), animado o fenomenal. Este no es un objeto para un yo pienso, sino un yo puedo, un sistema de potencialidades, un conjunto de significaciones vividas. La motricidad es un despliegue de potencias.

Desde el punto de vista de la Fenomenología, Husserl nos dice que el hombre es un "yo puedo corporal", es un sujeto en potencia. A pesar de que la motricidad sea multiplicidad, también tiene limitaciones, por ejemplo "no tengo la posibilidad de alejarme de mi cuerpo o de alejarlo a él de mí, y en correspondencia con ello las multiplicidades de aparición del cuerpo están en determinada manera restringidas: ciertas partes del cuerpo sólo puedo verlas en un peculiar acortamiento perspectivo, y otras (por ejemplo, la cabeza) son invisibles para mí”. (HUSSERL, 1997, p. 199). Yo no me puedo ver en movimiento, asistir a mi movimiento. Ante todo, este mi cuerpo, que se alimenta, que camina, que se mueve no es un objeto físico como lo es la máquina que es movida. ¿Hay una diferencia entre el movimiento de las cosas y el movimiento del propio cuerpo?

Barbarás (1992) a propósito nos dice: "yo digo de una cosa que es muda, pero mi cuerpo, él, se mueve, mi movimiento se despliega y repliega”. El cuerpo no se mueve porque una conciencia impulse un movimiento, aspecto que se 
desplegaría en la extensión geométrica. Mi movimiento, recalca Merleau-Ponty (1986, p. 18), no es una decisión del espíritu, el cuerpo puede moverse (Sich bewegen); en la medida en que el movimiento emana del propio cuerpo hay que admitir una percepción que le es propia; la motricidad ha de comprenderse lejos de ser la simple conciencia de mis cambios de lugar presentes o próximos.

Así, pues, la intencionalidad se puede caracterizar como un «yo puedo», según la expresión del propio Husserl, a condición de comprender este poder en el sentido de potencialidad; de allí que el movimiento corporal no pueda ser confundido con un desplazamiento o cambio de lugar en el espacio geométrico. Al plantear el yo puedo corporal como despliegue de potencias, reconocemos que el cuerpo tiene voluntad, decido o no ejecutar una práctica corporal como caminar danzar, jugar, etc. Mi cuerpo es el único que puede tener sensaciones orgánicas o ubiestesias, puede tener una multiplicidad de experiencias sensibles y kinestéticas; en cambio, de los objetos físicos, puedo adquirir sensaciones visuales y táctiles, mas solo mi cuerpo puede proporcionarme las sensaciones.

Siguiendo a Husserl, hay que distinguir que yo muevo mis manos y mis pies, yo muevo las partes individuales de mi cuerpo y percibo mis movimientos de una manera diferente a como percibo los movimientos de un cuerpo exterior porque, a la vez, percibo y soy percibiente. Cada gesto corpóreo es movido 'por mí' y, aunque yo no me vea moviéndome, si me percibo en movimiento. "Por experiencia sé que mis miembros corporales se mueven de la manera peculiar que los distingue de todas las otras cosas y de movimientos de cosas (movimientos físicos mecánicos): por el carácter del mover subjetivo, del yo muevo". (HUSSERL, I997, p. 304, § 60).

Cuando yo me muevo, el cuerpo es el portador de sensaciones (ubiestesias) o de sensibilidades. Por ejemplo, por medio del movimiento de los dedos tengo sensaciones de movimiento,

moviendo la mano sobre la mesa tengo experiencia de ella y de sus determinaciones có-
sicas. A la vez, en todo momento puedo poner atención en la mesa y encuentro en ellas
sensaciones táctiles, sensaciones de lisura y de frío, etc., al levantar una cosa experimento
su peso, pero a la vez tengo sensaciones de peso que tienen su localización en el cuerpo.
(HUSSERL, I997, p. I85, §36).

Estas sensaciones están ancladas al cuerpo vivido y se extienden al hecho objetivo, al estar en movimiento, es decir, como tienen una exposición proyectiva abarcan todos los contenidos de la sensación.

El cuerpo es el portador de potencias. Si, por ejemplo, yo toco mi mano derecha con la mano izquierda, la aparición de la mano izquierda y de la mano derecha se constituyen recíprocamente con las sensaciones táctiles y kinestésicas, 
moviéndose la una sobre la otra de tal o cual manera. Ahora bien, cuando toco mi mano derecha con mi mano izquierda, lo que toco y lo tocado no son otra cosa que mi propia corporalidad. A la vez que yo me muevo, igualmente un miembro del cuerpo se mueve y es movido por mí. Cuando yo hago mover mi mano, ese movimiento corporal es resultado que se da gracias a mí, es un yo me muevo. El moverse, actuar y expresar es inseparable de una visión de mundo, puesto que es aquí donde estoy cuando pienso, siento, imagino y deseo. En este sentido, Buytendijk citado por Van Den Berg ( 1952 ) establece "la relación hombre-situación porque al movimiento lo determina la situación en la que se encuentre el ser humano mismo y desde la situación".

Cuando Buytendijk ( 1957) diferencia entre el cuerpo que se mueve y aquel que es movido, menciona que solo aquel cuerpo que se mueve es asistido por un 'yo puedo' y cumple con las funciones que ligan al ser en situación, que son el sujeto que percibe, que actúa, que se expresa y que siente. Incluso, esto lo reafirma Weizäcker citado por Buytendijk ( 1957 ) cuando dice que "allí donde alguna cosa se mueve hay una presencia fenomenológica de la vida", pues el cuerpo abarca en sí la capacidad de moverse, de autokinesis y, también, como cuerpo agente, se abre al mundo y toma posición de la propia existencia.

Al considerar la motricidad como despliegue de potencias, discutimos con quienes explican el movimiento en términos de una fisiología organicista, mecanicista y causal, porque estas explicaciones son reducidas y no dan cuenta de lo que es el movimiento del propio cuerpo. Hay que decir, entonces, que soy yo quien me muevo y que dicho movimiento se da en primera persona, el cuerpo no aparece como una cosa en un punto del espacio que ha de ser conducida a otro lugar como si fuese un dispositivo mecánico. No necesito buscarlo para moverlo, está conmigo, no necesito conducirlo hacia el término del movimiento, porque mi cuerpo siempre está ahí.

\section{CONCLUSIÓN: LAS PRÁCTICAS CORPORALES COMO DESPLIEGUE DE POTENCIAS}

En síntesis, el movimiento corporal no se entiende como un movimiento objetivo ni como un desplazamiento en el espacio o como un simple cambio de lugar que se explica física y fisiológicamente. Más bien, lo que permite ver la motricidad en el horizonte de la Educación Corporal es que hay que asumir una postura crítica frente al concepto de movimiento corporal mecanicista para no reducirlo a un cambio de lugar ni al movimiento del brazo como máquina de músculos y huesos, ni como aparato de flexiones y extensiones. Esperamos liberar la motricidad de la 
explicación mecanicista y fisiologista. Por ello, las prácticas corporales tienen que ver con una experiencia vivida (Erlebnis) y se puede decir que el ser humano se orienta en su movimiento y este moverse no se efectúa automáticamente sino que presupone una voluntad, una disposición, un 'yo puedo'.

\begin{abstract}
Es posible reconocer que los gestos, la mímica, las posturas, la danza, los desplazamientos, entre otras formas de moverse, expresan emociones, manifiestan sentido y revelan una especificidad de la relación con el mundo perteneciente a una situación. El cuerpo dice en sus gestos, en su mímica, en sus posturas, en su danza y en sus desplazamientos, pero arrastra en su estela movimientos particulares que se hacen comprensibles en su propio contexto. El movimiento corporal abre al ser humano a la esfera del comportamiento como espacio propiamente humano, ya que las formas de moverse son modos de expresión del propio cuerpo. A través del movimiento corporal, el hombre se expresa, manifiesta algo e indica modos de ser. (GALLO, 2010, p. 76).
\end{abstract}

Las prácticas corporales representan una experiencia de potenciación. Mediante el movimiento corporal hay un lenguaje que simboliza, expresa y significa; por ello, la motricidad no escapa a la expresión simbólica del cuerpo; así, la danza, el juego, el caminar y el gesto son lenguajes que se manifiestan de una manera corporal y en perspectiva educativa nos ofrece sentidos a la experiencia de movernos, sentidos que no se reducen a la explicación, justificación o al beneficio; más bien son sentidos que no están referidos a una meta o a un fin ya dados, porque en vez de conducirnos a alguna parte o a una dirección única, nos conduce a varias partes o a una multiplicidad de direcciones.

Privilegiamos las prácticas corporales hedonistas, sensibles y que producen sentido, y refutamos esas formas dominantes de la educación técnica e instructiva que tiende hacia un "deber ser" y preferimos darle lugar a la experimentación estética; rechazamos lo homogéneo y tendemos a la potenciación de lo heterogéneo, rebatimos las formas hegemónicas que normalizan y optamos por formas potenciadoras de la experiencia corporal por medio del movimiento.

La experiencia de movernos no se queda en lo evidente, ni en la respuesta, ni en su funcionalidad (orgánica o técnica); cuando decimos que nos movemos ello no significa que movemos sólo las manos, los pies o la cabeza, sino que nos movemos a nosotros mismos, movemos nuestras ideas y nuestras emociones; cuando movilizamos la mirada, se genera una apertura; cuando hay direccionalidades múltiples, se desplaza la mirada. El cuerpo que se mueve piensa, elige, crea, siente, imagina, de tal manera que todas las condiciones orgánicas participan del pensamiento, del sentimiento y de la voluntad. Si valoramos la motricidad sólo fisiológicamente, la estaremos funcionalizando como medio para otra cosa: el bienestar del organismo. 
Por ello, para la Educación Corporal interesa la Motricidad como la experiencia que nosotros mismos hacemos del cuerpo (leiblich). La experiencia es lo que nos pasa y lo que al pasarnos nos confiere sentido, la experiencia no es lo que te sucede, sino lo que haces con lo que te sucede ¿Por qué no interesa el movimiento evidente dirigido siempre hacia una finalidad? iQuizás porque lo evidente implica movernos dentro de una misma obviedad, de un modo repetitivo y sin distinción!

\section{Práticas corporais na educação corporal}

RESUMO: Este trabalho tem como objetivo abordar a motricidade a partir de práticas corporais, como dançar, jogar e caminhar, assim como o gesto e as sensações cinestésicas no horizonte da Educação corporal. Interessa mostrar a Motricidade como essa experiência que nós mesmos fazemos do Corpo (leiblich) para estabelecer uma relação com a Educação. A motricidade, no horizonte da Educação Física, realça as práticas corporais não com o fim de prescrever práticas institucionalizadas ou normatizadas, mas com a pretensão de favorecer experiências, e como este pathos ocorre, afetando, tocando-nos e atuando sobre nós mesmos, o que pressupõe examinar a Educação à luz do acontecimento, que não pretende planejar o sensível nem normatizar a experiência

PALAVRAS-CHAVE: Educação corporal; práticas corporais; motricidade; experiência do próprio corpo.

\section{Corporal practices in Corporal Education}

ABSTRACT: This work aims to approach the movement based on corporal practices such as dance, play and walk, as well as gesture and kinesthetic sensations on the perspective of Corporal Education. It is interested in showing the movement as the experience that we ourselves make about the corpse (leiblich) to establish a relationship with the Education. Movement, on the perspective of Corporal Education, enhance corporal practices not to prescribe institutionalized or standardized practices, but with the aim of encouraging experiences to provide affection states, like pathos that happens taking place, affecting, touching and acting on us, which assumes a view of Education in the form of the event, which does not intend to plan the sensitive or establishing experience.

KEYWORDS: Corporal Education; corporal practices; movement; experience of own corpse.

\section{REFERENCIAS}

AGAMBEN, G. Infancia e historia. Buenos Aires: Adriana Hidalgo, 2007.

BARBARÁS, R. Motricité et phénoménalité chez le dernier Merleau-Ponty. En: RICHIR, M.; TASSIN, E. Merleau-Ponty: phénoménologie et expériences. Grenoble: Jerôme Million, 1992. 
BENJAMIN, W. Dirección única. Madrid: Alfaguara, 1987. Infancia en Berlín hacia 1900. Buenos Aires: Alfaguara, 1990.

BUYTENDIJK, F. J. Attitudes et mouvements: étude fonctionnelle du mouvement humain. Paris: Desclée de Brouwer, 1957.

CASTRO, J.; URIBE, M. La educación somática: un medio para desarrollar el potencial humano. Educación Física y Deporte, Medellin, v. 20, n. I, p. 31-43, 1998.

DE SANTIAGO, L. Arte y poder: aproximación a la estética de Nietzsche. Madrid: Trotta, 2004. FARINA, C. Arte, cuerpo y subjetividad: estética de la formación y pedagogía de las afecciones. 2005. Tesis (Doctoral en Teoría e Historia de la Educación) - Universidad de Barcelona, Barcelona, 2005. Disponível em: <http://www.tdx.cesca.es/TESIS_UB/AVAILABLE/TDX0922105-05743//TESIS_CYNTHIA_FARINA.pdf $>$.

GADAMER, H-G. Verdad y método I. Salamanca: Sígueme, 2003.

GALLO, L. E.; CASTAÑEDA, G. La experiencia de la danza en la constitución de subjetividad. Revista Digital, Buenos Aires, v. 13, n. I30, 2009. Disponivel em: <http://www.efdeportes. com/efd I 30/la-experiencia-de-la-danza-en-la-constitucion-de-subjetividad.htm > .

GALLO, L. E. Los discursos de la Educación Física contemporánea. Bogotá: Kinesis, 2010. La educación corporal bajo la figura del acontecimiento. Revista Educación Física y Deporte, n. 30, p. 504-513, 2011.

GARCÍA, M. et al. Cuerpos a motor. Las Palmas de Gran Canaria: Centro Atlántico de Arte Moderno, 1997.

GUMBRECHT, H. Elogio de la belleza atlética. Buenos Aires: Katz, 2006.

HOLZAPFEL, C. Crítica de la razón lúdica. Madrid: Trotta, 2003.

HUSSERL, E. Chose et espace: leçons de 1907. Paris: Presses Universitaires de France, 1989. Libro segundo: investigaciones fenomenológicas sobre la constitución. México: Universidad Nacional Autónoma de México, 1997.

KRÜGER, H. La hermenéutica científico-espiritual. In: . Introducción a las teorías y métodos de la ciencia de la educación. 2. ed. Opladen: Leske y Budrich, 1999.

LARROSA, J. La experiencia de la lectura: estudios sobre literatura y formación. México: Fondo de Cultura Económica, 2003.

LE BRETON, D. Rostros: ensayo de antropología. Buenos Aires: Letra Viva e Instituto de la Máscara, 2010. 
MASSCHELEIN, J. Educar la mirada: la necesidad de una pedagogía pobre. Buenos Aires: Manantial, 2006.

MERLEAU-PONTY, M. El ojo y el espíritu. Barcelona: Paidos, 1986. Fenomenología de la percepción. Barcelona: Península, 1975. La estructura del comportamiento. Buenos Aires: Hachette, 1976.

NIETZSCHE, F. Así habló Zaratrustra. Madrid: Alianza, 2009. El nacimiento de la tragedia. Madrid: Biblioteca EDAF, 1998. La gaya ciencia. Madrid: Biblioteca EDAF, 2002.

PLESSNER, H. La risa y el llanto. Madrid: Revista de Occidente, 1960.

SCHILLER, F. Kallias: cartas sobre la educación estética del hombre. Barcelona: Anthropos, 1990.

ULRICH, H. Elogio de la belleza atlética. Buenos Aires: Katz, 2006.

VAN DEN BERG, J. H. The Human body and the significance of human movement: a phenomenological study. Philosophy and Phenomenological Research, Buffalo, v. I3, n. 2, p. $159-183$, dec. 1952.

WALDENFELS, B. Habitar corporalmente en el espacio. $\Delta \mu \square \square$ : Revista de Filosofía, v. 32, p. $21-37,2004$.

Recebido: 04 mai. 201 I

Aprovado: 30 jan. 2012 